\title{
Density Functional Study of Oxygen Reduction Reaction on Oxygen Doped Graphene
}

\author{
Jianping Sun and Xiaodong Liang \\ School of Electrical \& Electronic Engineering, North China Electric Power University, \\ Beijing 102206, P. R. China \\ sunjp@ncepu.edu.cn
}

\begin{abstract}
Oxygen doped graphene catalyzing Oxygen Reduction Reaction (ORR) was studied using density functional theory (DFT). The active site of the catalyst was studied, the ORR reaction path was analyzed, and the mechanism was discussed. The results show that similar to $\mathrm{N}$-doped graphene, ORR reaction intermediates absorbed on the neighbor carbon atom adjacent to the oxygen atom. The doped graphene has obviously catalytic effect on absorbed $\mathrm{OOH}$ and $\mathrm{O2}$, and the reaction follows the four-electronic transfer path.
\end{abstract}

Keywords-Oxygen Doped Graphene; ORR; Catalysis; DFT; Adsorption

\section{INTRODUCTION}

In recent years, with the rapid development of economy, the excessive use of fossil fuels such as coal and gas, and the resulting greenhouse effect and pollution of environment have posed a serious challenge to human survival. Low temperature proton exchange membrane fuel cell (PEMFC) can convert chemical energy through the electrode reaction directly into electrical energy with high efficiency. The reaction does not involve burning and the product is water, which cause less environmental pollution. So, it is regarded as an ideal power source replacement of traditional internal combustion engine. At present, one of the main problems hindering the industrialization of the fuel cell, is that oxygen reduction reaction (ORR) occurred on the cell cathode need precious metal platinum $(\mathrm{Pt})$ as catalyst, which has limited reserves and is costly.Therefore, raising the utilization rate, reducing consumption of platinum, and developing low cost, high performance and high stability of non-Pt catalyst become a hot research topic. $[1,2]$

Graphene is a two-dimensional carbon material composed of SP2 hybrid carbon atoms, with unique physical and chemical properties. Because of its good electrical conductivity, and catalytic activity after doping, graphene doped with non-metallic atoms as oxygen reduction reaction (ORR) catalytic electrode materials of fuel cells, is attracting more and more interests. [3] It was found that carbon nanotubes [4, 5] and graphene [6, 7] doped with $\mathrm{N}$ atoms possess good catalytic activity for ORR, which is equal or even higher than commercial Pt/C catalyst. Dai, et al. [4] argued that this kind of high catalytic activity is due to the larger electronegativity of $\mathrm{N}$ (3.04) compared to $C$ (2.55), which can generate positive charge density distribution at carbon atoms adjacent to the impurity. Positive charge is beneficial to $\mathrm{O} 2$ adsorption and elementary oxygen reduction reaction. In addition, smaller electronegativity elements than $\mathrm{C}$ atom are introduced into graphene, such as B [8-11] and P [12]. The results showed that doping atoms can change the electrical properties and chemical activity of graphene system, and have very good catalytic effect on oxygen reduction reaction. Recently, S-doped graphene has been synthetized through various methods, and showed catalytic activity comparable to $\mathrm{N}$-doped graphene system. [13-15]

In theoretical aspect, oxygen reduction reaction mechanism was studied on various nonmetallic element doped graphene based on density functional theory. The results showed that $\mathrm{N}$-doped graphene [16-18] and $\mathrm{S}$ doped graphene [19], are efficient catalysis for oxygen reduction reaction on the electrode. Yu, et al. [18] studied the impact of solvent and coverage on catalytic reaction in detail, and they agreed that "four-electron transfer pathways" in oxygen reduction reaction is the optimal path. $\mathrm{Xia}$, et al studied influence of the dopant position of $\mathrm{N}$ doped graphene on oxygen reduction-oxygen precipitation reaction [17], analyzed four configurations of S-doped graphene by using clusters model, and the path of the oxygen reduction reaction [19]. Being firstly found, much research works both experimental and theoretical focused on $\mathrm{N}$-doped graphene. Similar to $\mathrm{N}$, the electronegativity of $\mathrm{O}$ is larger than $\mathrm{C}$, but experimental and theoretical research on O-doped graphene system for oxygen reduction reaction catalysis are rarely reported. In this paper, using first principle calculation method based on density functional theory, O-doped graphene is studied as the catalysis of oxygen reduction reaction in acid environment, and the catalytic mechanism is discussed.

\section{METHODS}

In this paper, calculations on electronic properties of doped graphene and its adsorption properties were carried out, using Vienna ab-inito simulation package (VASP) based on spin-polarized density functional theory [20]. Projector-augmented wave (PAW) method describes the interaction between the ion core and electron. Electron exchange-correlation function is represented by the generalized gradient approximation (GGA), and the model of Perdew-Burke-Ernzerhof (PBE) is used for the nonlocal corrections. A kinetic energy cutoff of $500 \mathrm{eV}$ is used with a plane-wave basis set. Graphene cell uses $4 * 4 * 1$, a total of 32 atoms, with a vacuum space of $20 \AA$. The integration of Brillouin zone was conducted using the $11 * 11 * 1$ Monkhorst-Pack grid with the $\Gamma$-point included, and the 
error of the energy was set not larger than $0.01 \mathrm{eV}$. Atoms were relaxed and convergence precision was -0.02 . H, C, $\mathrm{O}$, and $\mathrm{S}$ atoms' valence electron configuration are respectively $\mathrm{H} 1 \mathrm{~s} 1, \mathrm{C} 2 \mathrm{~s} 22 \mathrm{p} 2$, O 2s22p4, and S 3s23p4. Spin was considered in the calculation. $+\mathrm{EM})$

Adsorption energy is defined as, Ead $=$ Egra $+M-($ Egra

Egra+M refers to the graphene system energy after doping atoms and adsorbing molecules, Egra refers the graphene system energy after doping atoms, EM is the energy of molecules. Free energy change $\Delta \mathrm{G}: \Delta \mathrm{G}=\Delta \mathrm{E}+$ $\Delta \mathrm{ZPE}-\mathrm{T} \Delta \mathrm{S}$. Free energies of the ORR intermediates in electrochemical reaction pathways were calculated based on a computational hydrogen electrode (CHE) model suggested by Nørskov et al., here $\Delta \mathrm{E}$ is the total energy change directly obtained from DFT calculations, $\triangle \mathrm{ZPE}$ is the change in zero-point energies, $\mathrm{T}$ is temperature(298.15 $\mathrm{K})$, and $\Delta \mathrm{S}$ is the change in entropy.

\section{RESULTS AND DISCUSSION}

\section{A. Oxygen-doped graphene}

As shown in Fig. 1 (a), $4 * 4 * 1$ graphene cell, a total of $32 \mathrm{C}$ atoms, are selected. Replaced one $\mathrm{C}$ with $\mathrm{O}$ atom, $\mathrm{O}$-doped graphene system model was built. In the figure, the yellow circles denote $\mathrm{C}$ atoms, and the pink circle is $\mathrm{O}$. It is generally accepted that dopant atoms and the nearby $\mathrm{C}$ atoms form bonds in doped graphene, resulting in electronic charge density redistributes. The charged atoms could be the catalytic active positions. Therefore, researchers first discussed ORR catalytic activity position of O-doped graphene by analysis of charge distribution and density of states.

After optimizing the structure of above model, Bader charge analysis is used for each atom of O-doped graphene system to obtain quantity of charge. The charge distribution of $\mathrm{O}$ and nearby $\mathrm{C}$ atoms is shown in Fig. 1 (b). The charge on the $\mathrm{C}$ atoms in intrinsic graphene is very small, and evenly distributed. In contrast, charge redistribution happened after doping. That is, net charge distributed on the dopant and other atoms. In the figure, the red balls denote positively charged atoms, and the green ones are negatively charged atoms. Negatively charged $\mathrm{O}$ atom gains $1.045 \mathrm{e}$, while three positively charged adjacent $\mathrm{C}$ atoms lose $0.0645 \mathrm{e}, 0.2093 \mathrm{e}, 0.2093 \mathrm{e}$, respectively.

Zhang et al. [17, 21] studied ORR catalytic mechanism of N-doped graphene in the fuel cell, showing that ORR catalytic active sites are closely related to unevenly distributed charge. Therefore, the $\mathrm{C}$ atoms of intrinsic graphene do not have catalytic activity. After doping, the $\mathrm{N}$ atom was negatively charged, while the $\mathrm{C}$ atoms adjacent to the $\mathrm{N}$ atom lost electrons and became positively charged. These $\mathrm{C}$ atoms act as the catalytic active sites of ORR. Like $\mathrm{N}$-doped graphene, in O-doped graphene, the results show that the $\mathrm{O}$ atom gains electrons, negatively charged. The $\mathrm{C}$ atoms adjacent to the $\mathrm{O}$ became positively charged, showing that charge transferred between $\mathrm{O}$ atom and the nearby $\mathrm{C}$ atoms.
Analysis of partial density of states (PDOS) variation before and after doping is a common method to study interaction between atoms and the charge transfer. Fig. 2 shows the calculated total density of states (TDOS) of Odoped graphene, and partial density of states (PDOS) of S and neighbor $\mathrm{C}$ atoms. Among them, (a) shows total density of states of O-doped graphene, (b) shows density of state of $\mathrm{O}$ atom, (c) shows density of state of neighboring $\mathrm{C}$ atoms. For comparing, the figure also shows the density of state of an isolated $\mathrm{O}$ atom and a $\mathrm{C}$ atom in intrinsic graphene. Here, (d) shows isolate $\mathrm{O}$ atom, (e) shows $\mathrm{C}$ atom in intrinsic graphene; In addition, in terms of different types of valence electrons involved in bonding, in (b), (c), (d) and (e), the black lines denote $s$ state partial density of state, the red line denotes $\mathrm{p}$ state partial density of state.

From Fig. 2 (b), (c), it can be seen that $\mathrm{O}$ and $\mathrm{C}$ atoms in graphene strongly interacted, after doping. There are evident overlaps between the electronic states of two atoms. The main interaction occurs between $\mathrm{p}$ electronic states of $\mathrm{O}$ and $\mathrm{C}$, as shown in (b). Two resonance peaks in $\mathrm{O}$ atomic partial density of states appeared. One is located around the Fermi level, and another one is located $4 \mathrm{eV}$ above Fermi level. There also formed a weak energy band between $-4 \mathrm{eV}$ and $-8 \mathrm{eV}$ under the Fermi level, as shown in Fig. (d). Compared to isolated atom, after being doped into graphene, the energy levels of $\mathrm{O}$ atom split and extended into bands. Because the density of states $4 \mathrm{eV}$ above Fermi level corresponds to the empty state, or with no electrons filling, Fig. 2 (b) shows that $\mathrm{O}$ atom loses electrons after doping. Similarly, comparing Fig. 2 (c) and (e) to analysis of electronic gain and loss on $\mathrm{C}$ atoms in graphene. It can be seen that the Fermi level is in the middle of band gap in Fig. (e), density of state is almost zero at Fermi level, and the Fermi level is shifted to the high energy after doping. The peaks of density of state appeared, making the former empty states occupied by electrons, showing that the atom gaining electrons. The above results are consistent with the results obtained by Bader charge analysis.

It is generally accepted that positively charged atoms are conducive to adsorption of intermediates or atom groups in ORR, becoming the catalytic activity sites. Therefore, the active sites of $\mathrm{N}$-doped graphene are $\mathrm{C}$ atoms adjacent to $\mathrm{N}$ atoms. Like $\mathrm{N}$-doped graphene, carbon atoms adjacent to dopant oxygen atom obtained positive charges after doping. As a reasonable inference, the active sites of $\mathrm{O}$-doped graphene are also $\mathrm{C}$ atoms. The following ORR reaction process optimization showed that $\mathrm{O} 2$ and $\mathrm{OOH}$ tended to adsorbed on $\mathrm{C}$ atoms adjacent to $\mathrm{O}$, which confirmed this conclusion.

\section{B. ORR reaction paths}

The research shows that ORR on the fuel cell cathode has two paths, one is four-electron transfer path, $\mathrm{O} 2+4 \mathrm{H}+$ $+4 \mathrm{e}-\rightarrow 2 \mathrm{H} 2 \mathrm{O}$, and $\mathrm{O} 2$ is directly reduced into $\mathrm{H} 2 \mathrm{O}$, without the formation of intermediate $\mathrm{H} 2 \mathrm{O} 2$. Another one is two-electron transfer way, $\mathrm{O} 2+2 \mathrm{H}++2 \mathrm{e}-\rightarrow$ 


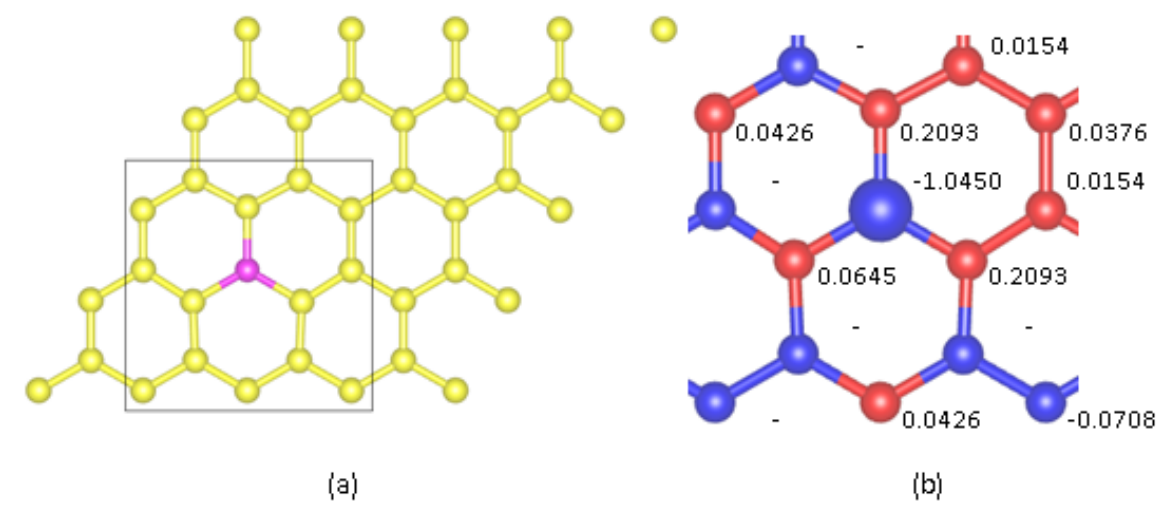

Figure 1. (a) Oxygen-doped graphene structure; (b) Charge distribution on atoms in the aquare.

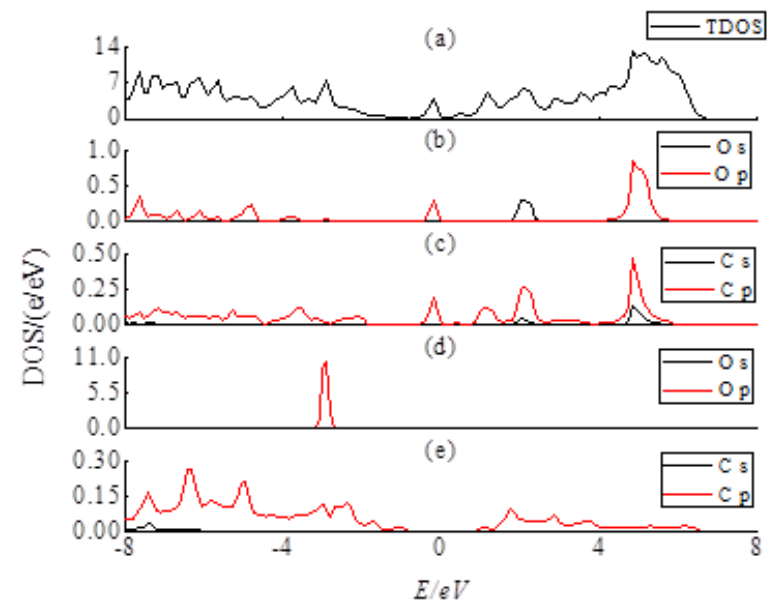

Figure 2. (a) total density of states of oxygen-doped graphene; (b) partial density of states of oxygen atom in oxygen-doped graphene; (c) partial density of states of carbon atom in oxygen-doped graphene; (d) density of states of isolated oxygen atom; (e) partial density of states of carbon atom in intrinsic graphene;

$\mathrm{H} 2 \mathrm{O} 2$, producing intermediate $\mathrm{H} 2 \mathrm{O} 2$. The former path is more efficient. Zhang et al.[17] have found that fourelectron transfer path dominated in the ORR reaction of doped graphene, therefore researchers are more interested in four- electron path and will discuss it.

There are two different mechanisms (Path I and II) following Yeager's dissociative mechanism or Damjanovic's mechanism [19], as follows.

$$
\begin{aligned}
& \text { Path I } \\
& \mathrm{O}_{2}+\mathrm{G} \rightarrow \mathrm{G}_{-} \mathrm{O}_{2} \\
& \mathrm{G}-\mathrm{O}_{2}+\mathrm{H}^{+}+\mathrm{e}^{-} \rightarrow \mathrm{G}-\mathrm{OOH} \\
& \text { Path II } \\
& \mathrm{O}_{2}+\mathrm{H}^{+}+\mathrm{e}^{-} \rightarrow \text { OOH } \\
& \mathrm{OOH}+\mathrm{G} \rightarrow \mathrm{G}-\mathrm{OOH} \\
& \mathrm{G}-\mathrm{OOH}+\mathrm{H}^{+}+\mathrm{e}^{-} \rightarrow \mathrm{G}-\mathrm{O}+\mathrm{H}_{2} \mathrm{O} \\
& \mathrm{G}-\mathrm{O}+\mathrm{H}_{2} \mathrm{O}+\mathrm{H}^{+}+\mathrm{e}^{-} \rightarrow \mathrm{G}-\mathrm{OH}+\mathrm{H}_{2} \mathrm{O} \\
& \mathrm{G}-\mathrm{OH}+\mathrm{H}_{2} \mathrm{O}+\mathrm{H}^{+}+\mathrm{e}^{-} \rightarrow \mathrm{G}+2 \mathrm{H}_{2} \mathrm{O} \\
& \mathrm{O}_{2}+\mathrm{H}^{+}+\mathrm{e}^{-} \rightarrow 2 \mathrm{H}_{2} \mathrm{O}
\end{aligned}
$$

In the equations, G, G-O, G-O2, G-OH, G-OOH denotes $\mathrm{O}$-doped graphene, O-doped graphene adsorbed with $\mathrm{O}$, O-doped graphene adsorbed with $\mathrm{O} 2$, O-doped graphene adsorbed with $\mathrm{OH}, \mathrm{O}$-doped graphene adsorbed with $\mathrm{OOH}$, respectively.
ORR four-electron transfer steps simulation are shown in Fig. 3. Firstly, OOH adsorbs on the surface of O-doped graphene, forming $\mathrm{G}-\mathrm{OOH}$ after optimization, as shown in Fig. 3 (a). Then, $\mathrm{H}$ is added to the structure and made close to the $\mathrm{O}$ atom far from the graphene plane in $\mathrm{OOH}$. After optimization, researchers find that $\mathrm{O}-\mathrm{O}$ bond is broken, forming a $\mathrm{H} 2 \mathrm{O}$ molecule and $\mathrm{O}$ atom adsorbed on graphene (G-O), as shown in Fig. 3 (b). After that, adds the second $\mathrm{H}$ to the structure, and make it closing to the G-O, forming $\mathrm{G}-\mathrm{OH}$ after optimization, as shown in Fig. 3 (c). In the end, adds the third $\mathrm{H}$ into the system, resulting in $\mathrm{C}$ $\mathrm{O}$ bond breaking and the second $\mathrm{H} 2 \mathrm{O}$ forming, as shown in Fig. 3 (d). The above simulation shows that ORR catalyzed by O-doped graphene follows four- electron transfer paths indeed.

Table 1 shows, adsorption energy, adsorption distance, the distance between atoms and charge transfer when graphene adsorbs different intermediate forming G-OOH, $\mathrm{G}-\mathrm{O} 2$, G-OH and G-O. In the four-electron reaction, adsorption of $\mathrm{OOH}$ or $\mathrm{O} 2$, is the first step of ORR, and is also a key step. This is because that $\mathrm{O}-\mathrm{O}$ bond rupture is the prerequisite of four-electron transfer path occurring. Dissociation energy of molecular state $\mathrm{O}-\mathrm{O}$ bond can be as high as $494 \mathrm{KJ} / \mathrm{mol}$. However, after adsorbing on graphene, because $\mathrm{C}$ and $\mathrm{O}$ atoms have stronger interaction, $\mathrm{O}-\mathrm{O}$ bond energy can be significantly reduced, making 
subsequent $\mathrm{O}-\mathrm{O}$ bond rupture reaction possible. Therefore, researchers first focused our study on the states of doped graphene after adsorption of $\mathrm{OOH}$ and $\mathrm{O} 2$.

Fig. 4 shows the structure of O-doped graphene adsorbing $\mathrm{OOH}$ before and after optimization. Here, letter a, a' stand for the structures before optimization, and b, b' stand for the optimized structure. Letter $a, b$ stand for the side view before and after optimization, and a' b' stand for vertical view before and after optimization. The yellow balls denote $\mathrm{C}$ atoms, pink balls $\mathrm{O}$ atoms, and brown balls $\mathrm{H}$ atoms. $\mathrm{O}$ atom initially is placed on the top of $\mathrm{C}$ atom, and $\mathrm{OOH}$ perpendicular to the surface of graphene. After optimization, $\mathrm{C}$ atom close to dopant $\mathrm{O}$ sticks out of graphene plane of $0.7324 \AA$, as shown in Table 1 , which forms a tetrahedron structure, as shown in Fig. 4(b). $\mathrm{O}$ and $\mathrm{C}$ atoms getting close to each other, the length of $\mathrm{C}-\mathrm{O}$ bond is $1.263 \AA$, while the length of O-O bond is $2.2326 \AA$, as shown in Table 1 . The energy of graphene adsorbing $\mathrm{OOH}$ is $-2.311 \mathrm{eV}$. After optimization, $\mathrm{O}-\mathrm{O}$ bond length in $\mathrm{OOH}$ increases from the isolated state of $1.320 \AA$ to $2.2326 \AA$. It shows that, $\mathrm{OOH}$ and graphene form strong chemical bond. At the same time, the adsorption weakens $\mathrm{O}-\mathrm{O}$ bond, causing increases of the bond length.

In order to understand the catalytic effect deeply, researchers further studied the related mechanism by the density of states analysis. Fig. 5 shows density of states of O-doped graphene adsorbed with $\mathrm{OOH}$. Here, Fig. (a) represent the total density of states of the system, and (b) for the partial density of state of $\mathrm{O}$ atom, (c) for partial density of state of $\mathrm{C}$ atom near the $\mathrm{OOH}$, (d) for partial density of state of $\mathrm{O}$ atom near to impurity $\mathrm{O}$ atom, (e) for partial density of state of $\mathrm{O}$ atom far away from impurity $\mathrm{O}$ atom, (f) for partial density of state of $\mathrm{H}$ atom. The black lines denote s state partial state density, and red lines denote $\mathrm{p}$ state partial state density.

Fig. 6 shows partial density of states of the dopant $\mathrm{O}$ atom before and after adsorption of $\mathrm{OOH}$, including (a) before adsorbing $\mathrm{OOH}$, (b) after adsorbing OOH. Fig. 7 shows partial density of state of $\mathrm{O}$ atom in $\mathrm{OOH}$ before and after adsorption, in which $\mathrm{O}$ is the one close to dopant $\mathrm{O}$ atom. Here, Fig. (a) is before adsorption, and (b) after adsorption.

Comparing Fig. 5 with Fig. 2, researchers can see that, before and after adsorbing $\mathrm{OOH}$, the density of state of the system changed, especially the dopant $\mathrm{O}$ atom. From Fig. 6 (b), researchers can clearly see that, compared with Fig. (a) that before adsorption, in $0 \sim 4 \mathrm{eV}$ energy range above Fermi level, the $\mathrm{p}$ electronic state density peak broadened and lowered noticeably. As the states above Fermi energy level are not occupied by electrons, researchers can infer that dopant $\mathrm{O}$ gain electrons after adsorption. Similarly, from Fig. 7(a) and (b) researchers can clearly see that after adsorption, $\mathrm{O}$ atom states as a whole are shifted to low energy, and the density of states peaks broadened. The states below the Fermi level, are corresponding to electrons occupied states. So, it shows that $\mathrm{O}$ atom gets electrons after adsorption. Because the HOMO orbital in $\mathrm{OOH}$ is antibonding orbital, electrons filling will weaken the bond strength of $\mathrm{O}-\mathrm{O}$ in $\mathrm{OOH}$, further resulting in the bond broken and the $\mathrm{H} 2 \mathrm{O}$ generation.

Bader analysis results are presented in table I. From the table, $\mathrm{OOH}$ gains overall 2.054e electron charge after adsorption. After further analysis, researchers find that the dopant $\mathrm{O}$ atom loses 1.216e electron charges after adsorption. Therefore, the gained charge of $\mathrm{OOH}$ should be partly derived from the $\mathrm{C}$ atoms, and partly from the dopant $\mathrm{O}$ atom, which plays the role of a bridge. From Fig. 6 , researchers can see that, in addition to $\mathrm{p}$ electron states, $\mathrm{s}$ electron states also evidently changed, and simultaneously filling of the states, which could be attributed to the change of $\mathrm{O}$ atomic hybrid states after adsorption. It is important to further analyze and understand catalysis mechanism of $\mathrm{O}$-doped graphene.

Adsorption process of $\mathrm{O} 2$ on the graphene is also optimized, and the results are similar to $\mathrm{OOH}$ adsorption. After O-doped graphene adsorbing $\mathrm{O} 2$, the $\mathrm{C}$ atom near to the dopant $\mathrm{O}$ atom protrudes graphene plane with $0.8812 \AA$ forming a tetrahedron structure. The length of $\mathrm{C}-\mathrm{O}$ bond is $1.4111 \AA$, and the length of O-O is $1.5212 \AA$, as shown in table 1 . The length of $\mathrm{O}-\mathrm{O}$ bond changes from the isolated state of $1.320 \AA$ to $1.5212 \AA$. Compared with the adsorption of $\mathrm{OOH}, \mathrm{O}$-doped graphene has less impact on $\mathrm{O}-\mathrm{O}$ bond interaction. At the same time, the adsorption energy of $\mathrm{O} 2$ is $0.856 \mathrm{eV}$, less than the adsorption energy of $\mathrm{OOH}$ $2.311 \mathrm{eV}$. It suggests that, because O-doped graphene has larger adsorption energy to $\mathrm{OOH}, \mathrm{G}-\mathrm{OOH}$ is more stable than G-O2 in energy, which could infer that $\mathrm{OOH}$ adsorption in the first electron transfer step reaction may be a more possible way to happen in ORR.

TABLE I. THE COMPUTATION RESULT OF OXYGEN-DOPED GRAPHENE ADSORPTION INTERMEDIATES

\begin{tabular}{|c|c|c|c|c|c|}
\hline & $\mathrm{d} / \check{\mathrm{A}}$ & $\overline{\mathrm{C}-\mathrm{O} / \mathrm{A}}$ & 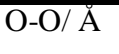 & $E_{a d} / \mathrm{eV}$ & $\Delta Q / \mathrm{e}$ \\
\hline $\begin{array}{c}\text { Gra- } \\
\text { O }\end{array}$ & 0.7712 & 1.2510 & I & -5.7800 & 1.7505 \\
\hline $\begin{array}{c}\text { Gra- } \\
\mathrm{OH}\end{array}$ & 0.6850 & 1.3737 & / & -3.1310 & 0.4615 \\
\hline $\begin{array}{c}\text { Gra- } \\
\mathrm{O}_{2}\end{array}$ & 0.8812 & 1.4111 & 1.5212 & -0.8560 & 2.4422 \\
\hline $\begin{array}{l}\text { Gra- } \\
\text { OOH }\end{array}$ & 0.7324 & 1.2630 & 2.2326 & -2.3110 & 2.0540 \\
\hline
\end{tabular}

(G-O, G-OH, G-O2, G-OOH are oxygen-doped graphene adsorbed intermediates; $\mathrm{d}$ is the distance between $\mathrm{C}$ and the graphene; $\mathrm{C}-\mathrm{O}$ is the distance between $\mathrm{C}$ and $\mathrm{O}$; $\mathrm{O}-\mathrm{O}$ is the distance between $\mathrm{O}$ and $\mathrm{O}$; Ead is adsorption energy; $\Delta \mathrm{Q}$ is charge transfer of adsorbed intermediates) 


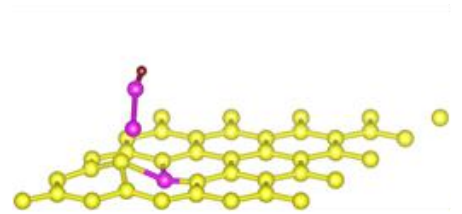

(a)

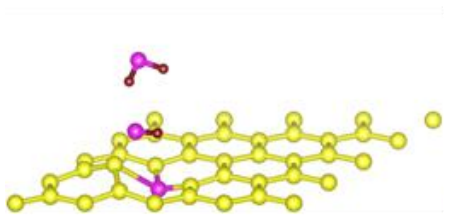

(c)

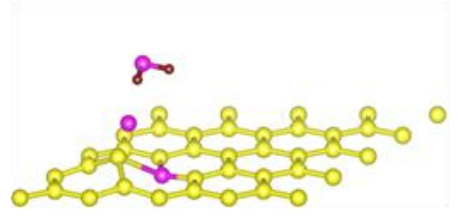

(b)

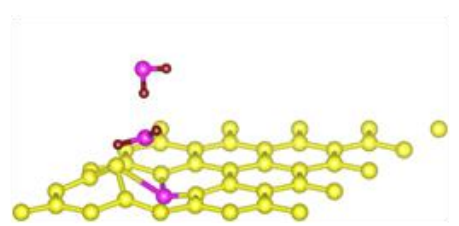

(d)

Figure 3. Four-electron pathway of ORR (a) oxygen-doped graphene adsorbing $\mathrm{OOH}$; (b) O-O bond broken after first $\mathrm{H}$ introduced, and one $\mathrm{H} 2 \mathrm{O}$ is generated; (c) Second $\mathrm{H}$ is introduced into structure and $\mathrm{OH}$ is generated; (d) the third $\mathrm{H}$ is introduced, and another $\mathrm{H} 2 \mathrm{O}$ is generated.

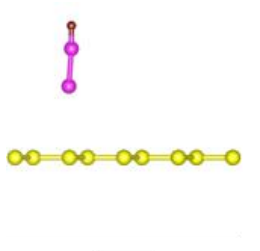

(a)

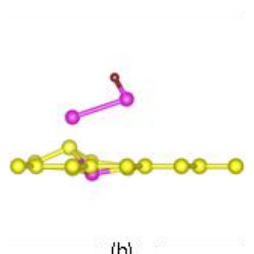

(b)

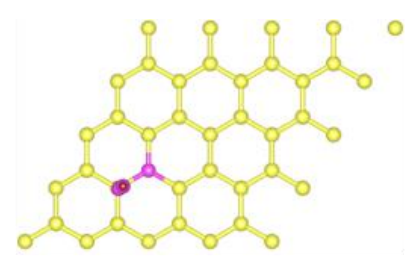

$\left\langle a^{\prime}\right.$

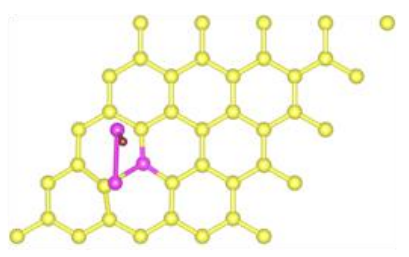

(b')

Figure 4. Oxygen-doped graphene adsorbing $\mathrm{OOH}$ initial structure (a) side view (a') top view; final structure (b) side view (b') top view. the yellow balls denote $\mathrm{C}$ atoms, the pink balls $\mathrm{O}$ atoms, and the brown ball is $\mathrm{H}$ atom.

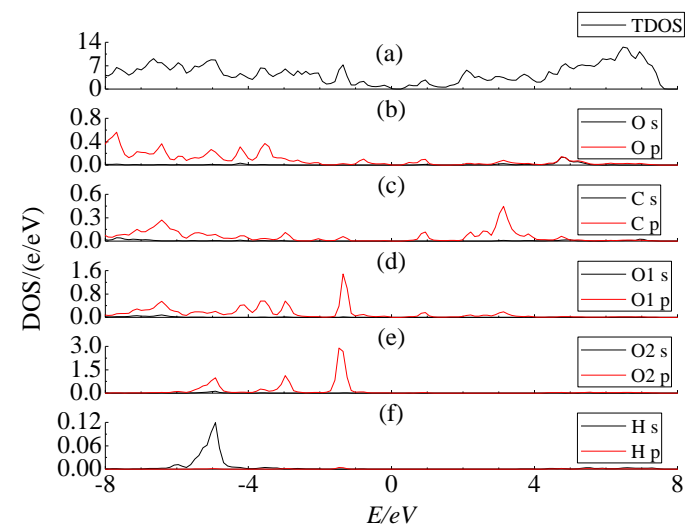

Figure 5. Density of states of oxygen-doped graphene adsorption OOH.(a) Total DOS; PDOS: (b) dopant $\mathrm{O}$; (c) $\mathrm{C}$ in graphene; (d) one $\mathrm{O}$ in $\mathrm{OOH}$; (e) another $\mathrm{O}$ in $\mathrm{OOH}$;(f) $\mathrm{H}$ in $\mathrm{OOH}$.

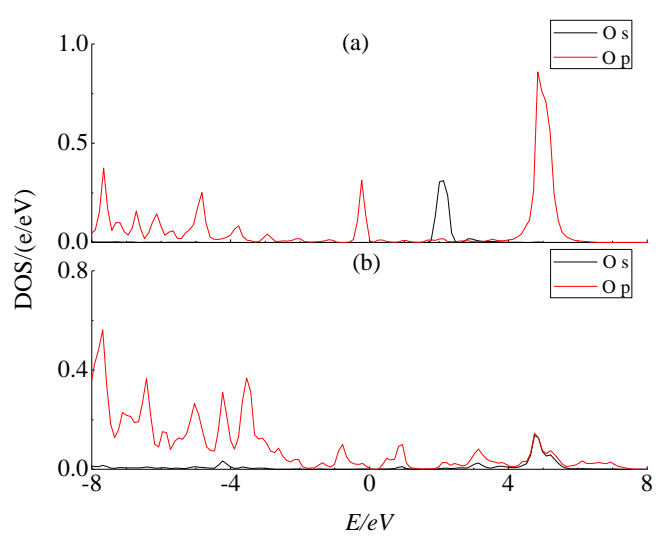

Figure 6. Partial density of states of the dopant $\mathrm{O}$ atom in oxygendoped graphene (a) before adsoption; (b) after adsorption. 


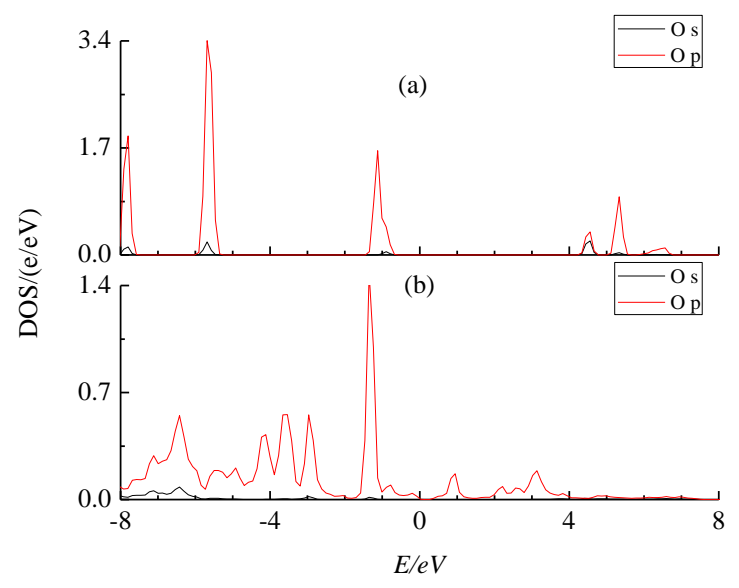

Figure 7. Partial density of states of oxygen atom in $\mathrm{OOH}$ (a) isolated $\mathrm{OOH}$; (b) adsorbed on graphene.

\section{CONCLUSIONS}

By using density functional theory (DFT), researchers studied the ORR catalytic reaction process occurring on the Oxygen-doped graphene. The results showed that, the catalytic active sites of ORR were $\mathrm{C}$ atoms adjacent to the dopant $\mathrm{O}$ atom. Through analysis of the charge distribution and the density of states, researchers found that $\mathrm{C}$ atoms adjacent to dopant $\mathrm{O}$ atom lost electrons, and positively charged. The optimization of various intermediates adsorption process showed that the ORR reaction occurring on O-doped graphene follows the way of four electrons path, in which $\mathrm{OOH}$ adsorption is more likely to happen than $\mathrm{O} 2$ adsorption. And further study is needed to understand the ORR mechanism of O-doped graphene, which has significance of guiding experimental works.

\section{REFERENCES}

[1] Sun, S. G.; Chen S. L., Electrocatalysis. Chemical industry press. 1st ed.;Beijing, 2013.

[2] Liu, M. M.; Zhang, R. Z; Chen, W. "Graphene-Supported Nanoelectrocatalysts for Fuel Cells: Synthesis, Properties, and Applications," Chem. Rev., 114(10), 2014,pp. 5117-5160.

[3] Kong, X. K.; Chen, C. L.; Chen, Q. W., "Doped graphene for metal-free catalysis," Chem. Soc. Rev., 43, 2014, pp. 2841-2857.

[4] Gong, K. P.; Du, F.; Xia, Z. H.; Durstock, M.; Dai, L. M., " Nitrogen-Doped Carbon Nanotube Arrays with High Electrocatalytic Activity for Oxygen Reduction," Science., 323, 2009, pp. 760-764.

[5] Yu, D. S.; Zhang, Q.; Dai, L. M., "Highly Efficient Metal-Free Growth of Nitrogen-Doped Single-Walled Carbon Nanotubes on Plasma-Etched Substrates for Oxygen Reduction," J. Am. Chem. Soc., 132(43), 2010, pp. 15127-15129.

[6] Qu, L. T.; Liu, Y.; Baek, J. B.; Dai, L. M., "Nitrogen-doped graphene as efficient metal-free electrocatalyst for oxygen reduction in fuel cells," ACS Nano, 4(3), 2010, pp. 1321-1326.

[7] Sheng, Z. H.; Shao, L.; Chen, J. J.; Bao, W. J.; Wang, F. B.; Xia.,X. H., "Catalyst-Free Synthesis of Nitrogen-Doped Graphene via Thermal Annealing Graphite Oxide with Melamine and Its Excellent Electrocatalysis," ACS Nano., 5(6), 2011, pp. 4350-4358.

[8] L. S. Panchokarla, K. S. Subrahmanyam, S. K. Saha,A. Govindaraj, H. R. Krishnamurthy, U. V. Waghmare and C. N. R. Rao, "Synthesis, structure, and properties of boron- and nitrogen-doped graphene," Adv. Mater., 21, 2009, pp. 4726-4730.
[9] Sheng, Z.H.; Gao, H.L.; Bao, W.J.; Wang, F.B.; Xia, X.H., "Synthesis of boron doped graphene for oxygen reduction reaction in fuel cells," J. Mater. Chem., 22, 2012, pp. 390-395.

[10] Wang, S.; Iyyamperumal, E.; Roy, A.; Xue, Y.; Yu, D.; Dai, L., "Vertically Aligned BCN Nanotubes as Efficient Metal-Free Electrocatalysts for the Oxygen Reduction Reaction: A Synergetic Effect by Co-Doping with Boron and Nitrogen," Angew. Chem., 50(49), 2011, pp. 11756-11960.

[11] Wang, S.; Zhang, L.; Xia, Z. H.; Roy, A.; Chang, D. W.; Baek, J. B.; Dai, L., "BCN Graphene as Efficient Metal-Free Electrocatalyst for the Oxygen Reduction Reaction," Angew. Chem., 51(17), 2012, pp. 4209-4212.

[12] Liu, Z. W.; Peng, F.; Wang, H. J.; Yu, H.; Zheng, W. X.; Yang, " Novel Phosphorus-Doped Graphite Layers with High Electrocatalytic Activity for O2 Reduction in Alkaline Medium," J. Chem. Int. Ed., 50, 2011, pp. 3257-3261.

[13] Yang, Z.; Yao, Z; Li, G. F.; Fang, G. Y.; Nie, H. G.; Liu, Z; Zhou, X. M.; Chen, X. A.; Huang, S. M., "Sulfur-Doped Graphene as an Efficient Metal-free Cathode Catalyst for Oxygen Reduction," ACS Nano., 6(1), 2012, pp. 205-211.

[14] Park, J. A.; Jang, Y. J.; Kim, Y. J.; Song, M. S.; Yoon, S.; Kim, D. H.; Kim, S. J., "Sulfur-doped graphene as a potential alternative metal-free electrocatalyst and Pt-catalyst supporting material for oxygen reduction reaction," Phys.Chem.Chem.Phys., 16(1), 2014, pp. 103-9.

[15] Chen, Y.; Li, J.; Mei, T.; Hu, X. G.; Liu, D. W.; Wang, J. C.; Hao, M.; Li, J. H.; Wang, J. Y.; Wang, X. B., "Low-temperature and one-pot synthesis of sulfurized graphene nanosheets via in situ doping and their superior electrocatalytic activity for oxygen reduction reaction," J. Mater. Chem. A., 2, 2014, pp. 20714-20722.

[16] Kim, H.; Lee, K; Woo, S. L.; Jung, Y. S., "On the mechanism of enhanced oxygen reduction reaction in nitrogen-doped graphene nanoribbons," Phys.Chem.Chem.Phys., 13, 2011, pp. 17505-17510.

[17] Zhang, L. P.; Xia, Z. H.; "Mechanisms of Oxygen Reduction Reaction on Nitrogen-Doped Graphene for Fuel Cells," J. Phys. Chem. C., 2011, 115(22), 2011, pp. 11170-11176.

[18] Yu, L.; Pan, X. L.; Cao, X. M.; Hu, P.; Bao, X. H., “Oxygen reduction reaction mechanism on nitrogen-doped graphene: A density functional theory study," J. Catal., 282, 2011, pp. 183-190.

[19] Zhang, L. P.; Niu, J. B.; Li, M. T.; Xia, Z. H., "Catalytic Mechanisms of Sulfur-Doped Graphene as Efficient Oxygen Reduction Reaction Catalysts for Fuel Cells," J. Phys.Chem.C., 118 (7), 2014, pp. 3545-3553.

[20] Kresse, G.; Furthmuller, "Efficient iterative schemes for ab initio total-energy calculations using a plane-wave basis set,"J. Phys.Rev.B., 54, 1996, pp. 11169.

[21] Zhang, L. P.; Niu, J. B.; Dai, L. M.; Xia, Z. H., "Effect of Microstructure of Nitrogen-Doped Graphene on Oxygen Reduction Activity in Fuel Cells," Langmuir, 28(19), 2012, pp. 7542-7550. 